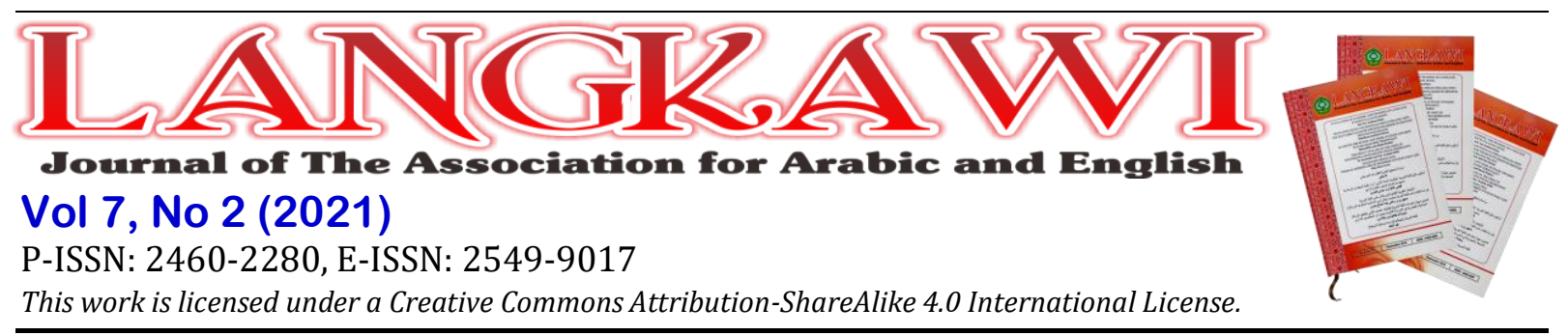

\title{
Transitivity of Try and V Construction in British and American English
}

\author{
Faisal Mustafa ${ }^{1 *}$, Syamsul Bahri Yusuf ${ }^{2}$ \\ ${ }^{1}$ Universitas Syiah Kuala, Banda Aceh, Indonesia. E-mail: faisal.mustafa@unsyiah.ac.id \\ ${ }^{2}$ Universitas Syiah Kuala, Banda Aceh, Indonesia. E-mail: s.bahri@unsyiah.ac.id \\ *Corresponding author
}

\author{
ARTICLE INFO \\ Keywords: \\ Corpus; Corpus analysis; Serial verb; \\ try and to; try and $V$
}

How to cite:

Mustafa, F., Yusuf, S.B. (2021).

Transitivity of Try and $V$

Construction in British and

American English. Langkawi: Journal

of The Association for Arabic and

English, 7(2), 197-211.

DOI:

http://dx.doi.org/10.31332/lkw.v7 i2.3166

\section{History:}

Received: 2021-09-12

Accepted: 2021-12-27

Published: 2021-12-30

\begin{abstract}
Try and $V$ construction is prevalent in British and American English. This construction is found in both spoken and written English, although with different frequencies. The verb in this construction only appears in in the base form. The lack of research on this verb formation leaves many aspects unexplored, one of which is the transitivity of the verb. Therefore, this study is intended to find out the number of arguments informed by this construction by matching the number of arguments to the verb try and the verb following it after the conjunction and. Two verbs were used to test this match, i.e., give and bring, which are three-place predicate verbs, and other two two-place predicate verbs, i.e., see and answer, were used to validate the finding. British National Corpus (BNC) and Corpus of Contemporary American English (COCA) were used to collect the data. The findings show that the number of arguments matched the verb following the conjunction and. Therefore, it can be concluded the number of arguments in try and $V$ construction is not unique to this construction, but it is similar to the try to $V$, where $V$ is the non-finite verb which selects the number of arguments. This result suggests that try and $V$ construction needs to be included in English grammar textbooks in order that non-native speakers can use and understand this rare grammatical rule in appropriate contexts.
\end{abstract}

\section{Introduction}

Most of verb constructions in English follow its standard rules, such as past participle after the verb have and base verb form after an auxiliary. However, some constructions only take certain verb forms. One of the famous examples of this construction is the use of gerund form after certain verbs. Another example is the use of subjunctive after certain verbs and adjectives like suggest, recommend, essential, and important. In addition, both American and British English allow $V$ and $V$ construction as in (1).

(1) a. To enable people who are ill with HIV/AIDS to live and die at home.

b. To enable people who are ill with HIV/AIDS to live at home. To enable people who are ill with HIV/AIDS to die at home.

In fact, the $V$ and $V$ construction is prevalent in English. Of 79,204 hits found on $\mathrm{BNC}, 22,394$ were in the base form. In this case, the conjunction is a coordinator that joins two simple sentences into a compound sentence. This process is presented in $(1 \mathrm{~b})$. However, some $\mathrm{V}$ and $\mathrm{V}$ constructions behave differently from the $V$ and $V$ construction in (1). One such is the try and $V$, discussion of which forms the focus of 
this research. Using similar analysis to that of (1), the sentence in (2a) is extracted into the two simple sentences shown in (2b) and (2c).

(2) a. I came here to try and be clear with you.

b. ${ }^{*}$ I came here to try (with you).

c. I came here to be clear with you.

Extracting the simple sentences from (2a) gives us grammatical sentences in $(2 b)$, and (2c) has a similar semantic meaning to that of (2a). However, the first sentence extracted from (2a) is not grammatical. The verb try is a two-place predicate in that it requires a subject and two objects, i.e., direct and indirect objects (Launey \& Mackay, 2011). In (2b), the complement clause is not present, making the sentence ungrammatical. This fact leaves us with the question as to what exactly try and $V$ is. This construction needs to be addressed, and Matsumoto (2020) suggests it be included in an English grammar textbook. The lack of adequate information about this construction makes it less convincing to include it in a grammar book. Therefore, this construction is alien for non-native speakers of English.

\subsection{Conditions for try and $V$ construction}

Sentence (3) shows that try and $V$ can be categorized as a verb because it syntactically shares the grammatical property of a verb. Radford (1997, p. 41) points out that only a base form of a verb can occur after auxiliaries. Like other Auxiliary $+\mathrm{V}$ constructions, an adverb can be inserted between auxiliary and verb (Azar \& Hagen, 2016, p. 453), as in (3e and f).

(3) a. I will try and hang on to the holiday.

b. They can try and guess how a story ends.

c. .... and may try and attack her or the handler when things go wrong.

d. You must try and find out why you did it.

e. A solitary horse will always try and join others.

f. I'd never try and separate him from his mother.

The other grammatical property of a verb proposed by Freudenthal, Ramscar, Leonard, and Pine (2021) is that it inflects for tense morphologically. Besides its base form, a verb has at most four inflected forms, formed by adding one of the suffixes to the base form, i.e., $+n$ for the past participle, $+d$ for past tense or past participle, $+s$ for the third person singular present tense, and +ing for progressive. Some verbs have inflected forms similar to the base form (Walker, 2017). In this case, try and $V$ behave differently from other verbs.

(4) a. Let me try and think of an example that isn't confidential.

b. *I tried and think of an example that isn't confidential.

c. *I have tried and think of an example that isn't confidential.

d. *She tries and think(s) of an example that isn't confidential.

e. *I am trying and think(ing) of an example that isn't confidential.

As in (4), try and $V$ only occurs in the base form. To confirm this generalization, we need to find out other conditions in which the base form of a verb occurs and test the try and $V$ in those conditions. Based on English syntax, the base form in English occurs in three clause constructions, i.e. imperative (Bolotov, Samorodova, Zakirova, 
\& Belyaeva, 2021), infinitival (Rivière, Oetting, \& Roy, 2018), and subjunctive (Kastronic \& Poplack, 2021).

(5) a. And do try and appear really keen, Perdit. (imperative)

b. I suggest that you try and pull yourself together. (subjunctive)

c. You'd be advised to try and view these videos on a stereo VCR. (infinitival)

d. I shall try and stick as close to Mota as possible. (infinitival)

In addition to the above conditions, there is one more condition in which the base form is used, i.e., after do-support, both in emphatic sentences and negative constructions in the present tense (Al-Makatrah, Yasin, Sulaiman, \& Al-Khawaldeh, 2017).

(6) a. I do try and keep people alive for a reasonable length of time.

b. He does try and say what he thinks.

c. I did try and warn you, Chief Inspector.

d. If she didn't try and make it up with him, he would change his mind.

e. He doesn't try and say what he thinks.

f. I didn't try and stop them

Examples from (5-6), extracted from BNC, confirm that try and $V$ occurs in all base form constructions. However, try and $V$ also occurs in the present tense when the subject is a first-person pronoun or a plural noun. Therefore, it leaves us with the question of whether plain verbs (verbs without suffix $+s$ or $+e s$ ) in the present tense have a zero tense marker or no marker at all. Huddleston and Pullum $(2005$, p. 31) do not share the idea that the base form is identical to the present tense form. In fact, almost all present tense forms are morphologically identical to the base form. However, the base form of the verb be is not identical to its present tense form as the idea of zero-marking is not supported in the present tense because the present tense forms of the verb be are not inflected forms of the base form. Another claim which supports the zero-marker idea is that if verbs in their present tense forms do not have any markers, there will be no marker to generate do-Support in negative and question sentences (Carden \& Pesetsky, 1977, p. 84), as shown in (7d).

(7) a. She understands these things.

b. She doesn't understand these things

c. I know $\varnothing$ what to say

d. I don't know what to say.

In $(7 a)$, the third person $-s$ marker triggers do-Support in (7b). Meanwhile, if the verb in $(7 \mathrm{c})$ does not have the present tense marker, the do-Support should not be triggered in $(7 \mathrm{~d})$.

\subsection{And as a fake coordinator}

The coordinator and in try and $V$ seem to be different from the coordinator and in other conditions. According to Anderson (2013, p. 65), one category can be preceded by the coordinator and is a finite VP, as illustrated in the following example.

(8) He dropped the pen and went on typing. 
However, in (8), there are two events: the dropping and the typing. This is not similar to the coordinator and in try and $V$, which denotes a single event. One of the coordinators and usages, which is quite similar to and in try and $V$, is when it is used to join a pair of words. However, this construction is partially or fully lexicalized (Huddleston, Payne, \& Peterson, 2002, p. 1287): in expressions such as buy and sell, come and go, tried and tested, where the words regularly go together. However, this is not similar to the coordinator and in try and $V$. In try and $V$, as the coordinator and joins the verb try with a lot of different verbs, the term lexicalized pairs cannot be applied. Because the coordinator and in try and $V$ are not similar to that in other conditions, Carden and Pesetsky (1977, p. 85) refer to this coordinator as a fake.

\subsection{Verb transitivity}

A declarative sentence expresses a proposition (Jary \& Kissine, 2019). A proposition consists of a predicate and a set of arguments (Rodríguez-Ferreiro, Andreu, \& Sanz-Torrent, 2014). The term predicate is used to refer to the word, which is typically a verb (Kroeger, 2004, p. 7), denoting an event described by a clause. This even involves arguments of the predicate, or traditionally termed as objects (Noble, Rowland, \& Pine, 2011, p. 964). The number of arguments taken by a predicate determines the type of the predicate, i.e., one-place predicate (intransitive), two-place predicate (transitive), or three-place predicate (ditransitive) (Bidgood et al., 2021; Shin, 2017, p. 12). A representation of the number and semantic roles of arguments of a predicate is called argument structure (Akbarnezhad, Sadighi, \& Bagheri, 2020). The argument for predicate includes agent ("causer or initiator of events"), patient ("entity which is acted upon, affected, or created; or of which a state or change of state is predicated"), beneficiary ("usually animate entity for whose benefit an action is performed"), recipient ("animate entity which receives or acquires something"), theme ("entity which undergoes a change of location or possession, or whose location is being specified"), and location (spatial reference point of the event) (Kroeger, 2004, pp. 5455). The argument structure of the predicate eat, for example, is an agent (the participant who performs the action of eat) and patient (the participant which is eaten). Meanwhile, the verb give receives three arguments, i.e., agent (who/what gives), recipient/beneficiary/ patient (who/what is affected), and theme (who/what is given), as illustrated below.

eat <agent, recipient>

give<agent, recipient/beneficiary/patient, theme/location>

\subsection{The present study}

To conclude, previous studies have addressed this construction, including its link to try to $V$ construction (Desurmont, 2011), its frequency in English corpora (Ross, 2018), its origin and variation across language variation and dialects (Hommerberg \& Tottie, 2007; Ross, 2013), and its historic trace (Tottie, 2012).This construction has been previously analyzed by Tsuchida (2011). They revealed that this construction only occurs in base form, and the coordinating conjunction "and" is just a pseudocoordination. However, we have not been presented with empirical data on whether the transitivity of try and $\mathrm{V}$ construction depends solely on the verb try or the verb following the conjunction. In addition, the function of the verb try in the construction has not been adequately addressed in previous research. Therefore, this research is 
intended to analyze the transitivity of try and $V$ construction and the function of verb try in the construction based on two corpora, British National Corpus (BNC) and Corpus of Contemporary American (COCA). The result of this study provides further information on the construction of try and $\mathrm{V}$ to substitute for what has been left out in previous studies. It is hoped that this study can make it more feasible to include this construction in English grammar textbooks for non-native speakers.

\section{Method}

This research is a quantitative research study which utilizes a corpus linguistics method. This research design is defined as a design that bases the results on a collection of corpus data analyzed quantitatively (McEnery \& Hardie, 2014). The data were extracted from two corpora accessed from Mark Davis' Corpora homepage (Davies, 2013), which was initially a part of Brigham Young University but moved outside the campus starting 2015. Since this study compares the use of try and $V$ construction in British and American English, the British National Corpus (BNC) and Corpus of Contemporary American English (COCA) were used to collect the data. BNC consists of 100 million words from written and spoken language in 1980-1993, and COCA consists of 425 million words in 1990-2019 (Davies, 2021). The keywords used for corpus search include:

- try and VERB $\rightarrow$ base form

- tries and _v? $\rightarrow$ singular form

- will try and VERB $\rightarrow$ future form

- _vb trying and _v?g $\rightarrow$ progressive form

- tried and _v?d $\rightarrow$ singular form

- have tried and_v?n $\rightarrow$ perfect from

- to try and VERB $\rightarrow$ infinitive form

The retrieved data were manually searched in order to eliminate cases in which the search results were not relevant, and repetition of the utterance due to either the copying or supplication data entry was eliminated. The data were categorized based on its subject, verb form, number of objects (intransitive, transitive, and ditransitive), and type of clauses, i.e., to-clause and other clauses.

Finally, for the primary objective of this study, i.e., to find out the transitivity of try and V construction in both English varieties, the number of arguments which the construction take was used as the basis for analysis. The number of arguments was matched the verb in the construction to be able to conclude whether the number of arguments depend on the verb try, verb following the conjunction and, or the construction itself, which means that the argument does not match either the verb try or the verb following the conjunction and. The semantic roles used in this research are based on those proposed by Kroeger (2004, p. 9). For this purpose, only the verbs give and bring were used because they have appeared as the frequent example for ditransitive verbs in many previous studies (Gerwin, 2013; Huelva Unternbäumen, 2015; Kim \& Rah, 2021; Kim, Shin, \& Hwang, 2020; Nisbet, 2020). The fact that both verbs are ditransitive verbs and try is a transitive verb can allow matching the number of arguments accurately. Collocations such as give up and bring in were eliminated for relevancy, and duplicate results due to copying were ignored. 


\section{Findings and Discussion}

This section presents the results of this corpus study and discusses them by reporting, interpreting, accounting for the results, and comparing the results to the literature. For systematicity, the section starts with presenting the difference between try and V constructions in British English and those in American English. Later, the transitivity of try and $\mathrm{V}$ construction in both accents is reported and discussed.

\subsection{Try and $V$ in British and American English}

It has been claimed that British and American English differ more in speech than in writing (Mair \& Leech, 2021). Using corpora of written and spoken language, this paper explored the extent to which this generalization holds for the use of try and $V$ in to-clauses and in other conditions in quantitative terms.

In BNC, 2477 tokens were found for try and $V$ in the base form. Of those total tokens, 1361 tokens were in written text. Furthermore, 994 tokens for try and $V$ occur in to-clauses and 367 tokens in other conditions such as after auxiliaries, dummy-do in positive (do, did) and negative forms (don't, didn't), and let-imperatives. In addition, 1116 tokens were found in spoken text, with 597 tokens in to-clauses and 519 tokens in other conditions. On the other hand, 3160 tokens for try and $V$ in base form were found in COCA. Likewise, 1082 of those tokens occurred in written text: 796 in to-clauses and 286 in other conditions. Furthermore, 2076 tokens occurred in spoken text, with 1596 in to-clauses and 482 in other conditions. The result of corpus analysis from BNC (for British English) and COCA (for American English) is summarized in the following table.

Table 1. The Distribution of Try and V in Spoken and Written British and American English (Raw Number and Percentage)

\begin{tabular}{llccc}
\hline \multirow{2}{*}{ Condition } & \multicolumn{3}{l}{ Written } & \multicolumn{3}{c}{ Spoken } \\
\cline { 2 - 5 } & BrE & AmE & BrE & AmE \\
\hline to-clause & $994(73 \%)$ & $796(73.5 \%)$ & $597(53.5 \%)$ & $1596(76.8 \%)$ \\
others & $367(27 \%)$ & $286(26.5 \%)$ & $519(46.5 \%)$ & $482(23.25)$ \\
Total & $1361(100 \%)$ & $1082(100 \%)$ & $1116(100 \%)$ & $2078(100 \%)$ \\
Total & \multicolumn{2}{c}{ 2443 (written) } & 3194 (spoken) \\
\hline
\end{tabular}

Table 1 shows the number of tokens and frequency of try and V found in British and American English corpora. To make it easier to compare the data, the numbers of tokens in Table 1 are presented in the following chart (figure 1).

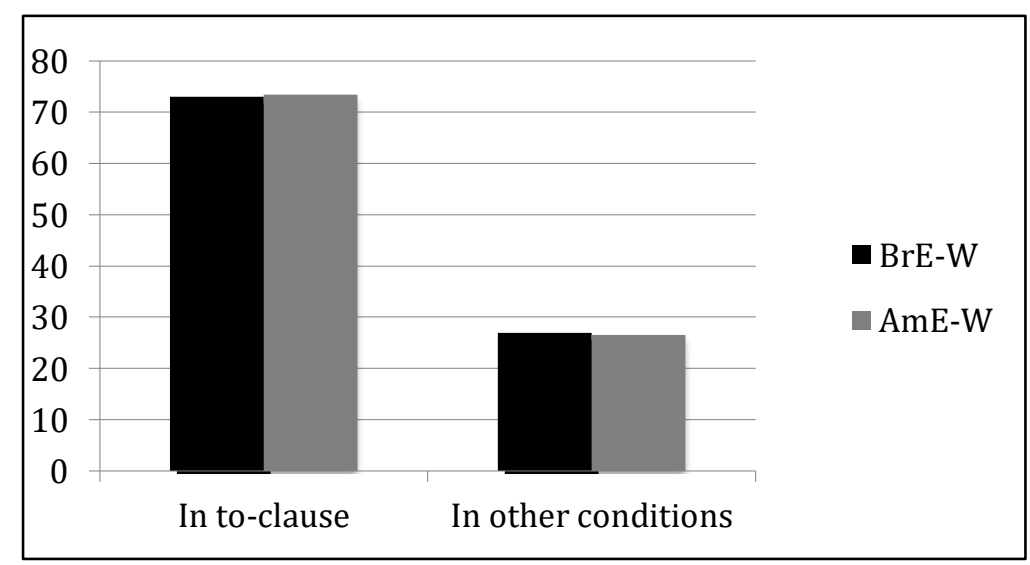

Figure 1. Try and $V$ in written British and American English 
The chart above shows that, both in written British and American English, try and $V$ mostly occurs in to-clauses. This finding is not unexpected. Biber, Johansson, Leech, Conrad, and Finegan (1999, p. 738) drew similar results from LSWE Corpus. Surprisingly, the percentages of the distribution of try and $V$, both in to-clauses and in other conditions, are very similar in British and American English, as previously reported by Brook and Tagliamonte (2016, p. 321). The figure 2 presents how written English's frequency differs from that in spoken English.

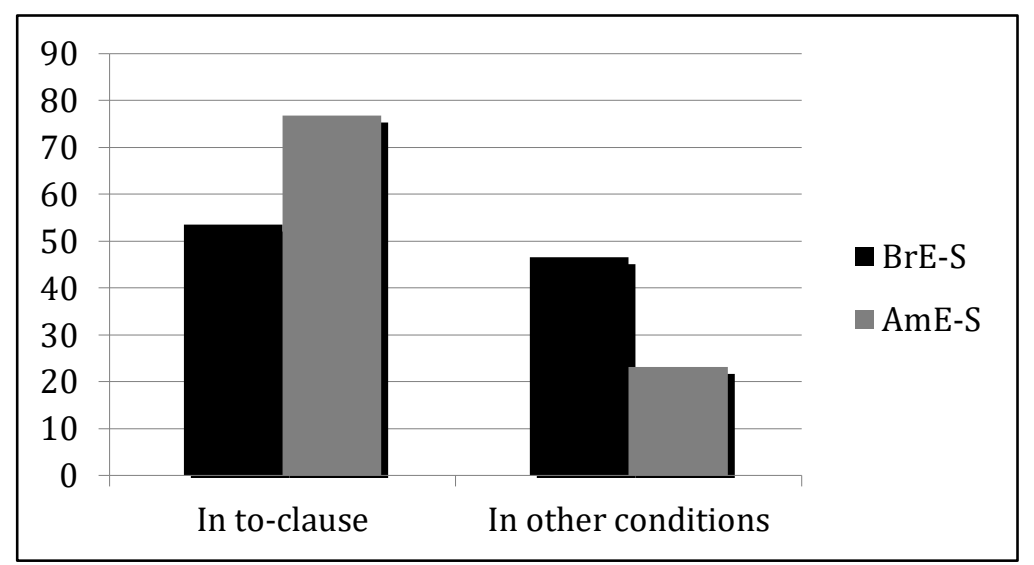

Figure 2. Try and $V$ in spoken British and American English

According to Figure 2, the try and $V$ occur in almost similar percentages across the two conditions. In spoken American English, however, the use of the try and $V$ is preferred in to-clauses, which is similar to the finding regarding writing. Therefore, Figure 2 illustrates an important finding: in spoken English, American and British forms tend to yield diverging distribution. Apparently, this finding suggests that British English contrasts more significantly with American English in speech than in writing. In addition, the data in Table 1 shows that try and $V$ construction is a feature of spoken American English, as in New Zealand English which appears in Newman and Rice (2008). However, the data shows that it is contrary to British English. Data from (Brook \& Tagliamonte, 2016, p. 319) also confirm that try and V construction was found more frequently in spoken British English than in American counterpart. Because the size of both corpora is not uniform and the coverage years are different, we cannot draw any conclusion about the preference in the genre - spoken or written between British and American English.

\subsection{Try and $V$ with 3rd-person singular in British and American English}

It was previously argued that try and $V$ only occur in the base form (Ross, 2018). Therefore, this construction is very unlikely to occur in an affirmative sentence in which the subject is $3^{\text {rd }}$-person singular and try and $V$ is the finite verb of the sentence, as shown in $(9 a)$. In examples $(9 b-h)$, however, the subjects are in the $3^{\text {rd }}$ person singular, but the verb remains in base form.

(9) a. *She tries/try and bite you.

b. She'll try and bite you if she sees you.

c. He does try and take a look at the signs they have.

d. He doesn't try and take a look at the signs they have.

e. Does he try and take a look at the signs they have?

f. He did try and take a look at the signs they have. 
g. He didn't try and take a look at the signs they have.

h. Did he try and take a look at the signs they have?

Based on the data presented in Table 3, the try and $V$ construction does take $3^{\text {rd }}$ person singular subjects, where the construction is not a definite verb. In addition, the frequency of $3^{\text {rd }}$ - person singular subjects is rather rare. In the following table, very detailed corpus data is illustrated. The $3^{\text {rd }}$ - person, singular forms in the analysis, including not only he and she, but it, as well as proper and common nouns. In the next column after the $3^{\text {rd }}$ person singular, for both English and American English, the numbers of tokens for all subjects, including the 3rd-singular person, are given for comparison.

Table 3. The Try and $V$ in a Sentence When $3^{\text {rd }}$ Person Singular is the Subject of the Sentence.

\begin{tabular}{lcccc}
\hline \multirow{2}{*}{ Condition } & \multicolumn{2}{c}{ British English } & \multicolumn{2}{c}{ American English } \\
\cline { 2 - 5 } & $\begin{array}{c}\text { 3rd_Person } \\
\text { Singular }\end{array}$ & $\begin{array}{c}\text { All } \\
\text { Subjects }\end{array}$ & $\begin{array}{c}\text { 3rd_Person } \\
\text { Singular }\end{array}$ & $\begin{array}{c}\text { All } \\
\text { Subjects }\end{array}$ \\
\hline S AUX try and V & $47(9.5 \%)$ & 495 & $97(19.5 \%)$ & 411 \\
S AUX NOT try and V & 3 & 11 & 2 & 23 \\
AUX S try and V & 2 & 23 & 2 & 3 \\
S * DO try and V & 0 & 27 & 0 & 41 \\
S DOES try and V & 0 & 0 & 2 & 3 \\
S DOES NOT/DOESN'T try and V & 0 & 0 & 3 & 6 \\
DOES S try and V & 0 & 0 & 1 & 1 \\
S DID try and V & 1 & 14 & 1 & 13 \\
S DID NOT/DIDN'T try and V & 3 & 10 & 4 & 21 \\
DID S try and V & 0 & 0 & 1 & 23 \\
\hline
\end{tabular}

Note: $S=$ Subject, $A U X=$ Auxiliary

Table 3 shows that try and $V$ can occur after an auxiliary, regardless of what the subject is. In both English varieties, the frequency of its occurrence falls dramatically when a negative marker follows the auxiliary and when the auxiliary is inverted in an interrogative sentence. After the dummy do in the past negative form ( $\left.d i d n^{\prime} t\right)$, in question forms and when do is used as emphatic expression, virtually no tokens are found in BNC or COCA. However, after the dummy do in the present negative form $\left(\right.$ doesn' $\left.^{\prime} t\right)$, in question forms and when does is used as an emphatic expression, try and $V$ does not occur in British English. Although it does occur in American English, the frequency is extremely rare. Meanwhile, the try and $V$ occur in base form, including AUX do, to do, and in interjection, but none is found in $3^{\text {rd }}$ person singular subject.

\subsection{Transitivity of try and $V$ construction}

Based on previous research studies, it is still unclear which verb determines the type of predicate and the selection of arguments for try and $V$ construction. There are three possible candidates responsible for this selection, i.e., try, verb following try and, and both. To determine the argument structure of the predicate try, a simple sentence 
shown in (10a) is a good starting point, and more complex sentences as shown in (10b) will be ignored for this analysis. For reasons of simplicity, simple sentences were used to analyze the three candidates.

(10) a. They try things first out of curiosity.

b. You should try to read as much as you can.

As shown in (11), the verb try is a two-place predicate because it takes two arguments, i.e., agent and patient or agent and outcome.

try <agent, patient/outcome>

Sentences in (11) are used to determine the argument structure of verbs following the try and. For this purpose, two verbs that occur in the try and V in BNC are selected.

(11)a. We give the child two pencils of equal length side-by-side.

b. They bring me much joy.

c. We have to try and bring him home.

The verb give and bring, in (11), are three-place predicates - the verb takes three arguments, as illustrated in the following.

give <agent, beneficiary, theme>

bring <agent, beneficiary, theme>

bring <agent, beneficiary, location>

After analysing the argument structure of both verbs, try and the verbs following the conjunction and, and comparing these argument structures with those of try and $V$ in Table 5 later, we will be able to decide which verb determines the selection of arguments in try and $V$. The table 4 shows the number of arguments for each verb in (11).

Table 4. Number of Arguments for Try and $V$ for Give and Bring

\section{Number of arguments}

\begin{tabular}{lcccccc} 
Try and .... & \multicolumn{3}{c}{ BrE } & \multicolumn{3}{c}{ AmE } \\
& 1 & 2 & 3 & 1 & 2 & 3 \\
\hline give (spoken) & $0(0 \%)$ & $2(10 \%)$ & $19(90 \%)$ & $0(0 \%)$ & $4(11 \%)$ & $33(89 \%)$ \\
bring (spoken) & $0(0 \%)$ & $0(0 \%)$ & $12(100 \%)$ & $0(0 \%)$ & $2(4 \%)$ & $52(96 \%)$ \\
give (written) & $0(0 \%)$ & $0(0 \%)$ & $9(100 \%)$ & $0(0 \%)$ & $6(8 \%)$ & $73(92 \%)$ \\
bring (written) & $0(0 \%)$ & $0(0 \%)$ & $13(100 \%)$ & $0(0 \%)$ & $1(2 \%)$ & $75(99 \%)$ \\
\hline
\end{tabular}

Table 4 shows that the number of arguments almost always matches the verb following conjunction and. However, this conclusion needs to be tested because it is possible that try and $V$ construction takes three arguments regardless of the verbs following the conjunction and. Therefore, the verbs see and answer were used for the validation because they take two arguments as in (12), and the results are provided in Table 5.

(12)a. I am going to try and see Steen.

b. The article is set out to try and answer some of your questions. 
The arguments involved with the verbs are illustrated in the following. see <agent, patient> answer <agent, patient>

Table 5. Number of Arguments for Try and V for See and Answer

\begin{tabular}{lcccccc}
\hline & \multicolumn{5}{c}{ Number of arguments } \\
Try and ... & 1 & 2 & 3 & 1 & AmE & 3 \\
\hline see (spoken) & $1(5 \%)$ & $20(95 \%)$ & $0(0 \%)$ & $4(22 \%)$ & $14(78 \%)$ & $0(0 \%)$ \\
answer (spoken) & $3(25 \%)$ & $9(75 \%)$ & $0(0 \%)$ & $2(9 \%)$ & $20(91 \%)$ & $0(0 \%)$ \\
see (written) & $0(0 \%)$ & $18(100 \%)$ & $0(0 \%)$ & $7(7 \%)$ & $100(93 \%)$ & $0(0 \%)$ \\
answer (written) & $0(0 \%)$ & $5(100 \%)$ & $0(0 \%)$ & $9(21 \%)$ & $33(79 \%)$ & $0(0 \%)$ \\
\hline
\end{tabular}

Table 5 shows that most the number of the arguments almost always match the verb following the conjunction and in BNC. There are some unexpected results in COCA, where some try and see and try and answer take one argument. However, the following example shows that another argument is understood from the previous sentence, as also shown by Gebhardt (2013, p. 177).

(13)a. Allaire sipped his beer as he stared down at the iPad, leaning closer to try and see [the iPad], adjusting his glass.

b. If you have a question, I will try and answer [the question] in the comment section ASAP.

Sentence (13b) shows that try and answer is a two-place predicate (if try and $V$ is considered as one verb), and it takes agent and patient as its arguments, which is similar to both the verb try and the verb following try and.

try and answer <agent, patient>

However, try and $V$ in Table 4 is not similar to the verb try. It is a three-place predicate. It has similar argument structures to those of the verb give, which is the verb following the conjunction and.

The result in Table 5 is expected, and it confirms that the number of arguments matches the verb following the conjunction and. All the tokens extracted from both BNC and COCA do not take three arguments, and thus the conclusion based on the data in Table 4 is confirmed. Therefore, the verb determining the type of predicate and number of arguments a try and $V$ takes is the $V$ (the verb following the conjunction and). This raises an important question of "What is the function of the verb try in the try and V construction?".

It has been shown that the verb try does not determine either the type of predicate or the selection of arguments of the try and $V$. In order to determine the initial function of try in the construction, we should analyze how the verb try is used. Hommerberg and Tottie (2007, p. 45) point out that the verb try can be used in two different ways, i.e. with to and and. When it is used with to, the verb try as in (10b) takes outcomes. It also has a non-finite complement, as it lacks an overt subject. However, in (14b), there is an understood subject of eating her salad, which is marked 
as PRO in this example. The primary subject, in this case, is the controller and the understood subject is the controller (Tallerman, 2020, p. 253). Therefore, when the verb try is used with to, it is called a control predicate (Kristoffersen, 2011, p. 259).

(14)a. She tried [to eat her salad]

b. She $i$ tried $\left[\mathrm{PRO}_{i}\right.$ to eat her salad]

In this less simple sentence, the argument structure of the verb try is <agent, outcome> rather than <agent, patient>, which is true in simple sentences, as shown previously in (10a).

Carden and Pesetsky $(1977$, p. 85$)$ have proposed that try and $V$ is a paraphrase of try to V. Citing evidence found in Longman Spoken and Written English Corpus (LSWE Corpus). The data in the current research, which shows that the number of arguments matches the verb following the conjunction and rather than the verb try, confirms that try and $V$ construction is originally try to $V$, which is also related to serial verb as discussed in Altakhaineh and Zibin (2018) and Roberts (2012). Biber et al. (1999, p. 738) suggest the reason for this paraphrasing is that the use of conjunction and is to avoid the repetition of to because the try and $V$ is mostly found when the construction is in a to-clause, which is supported by our data where $73 \%$ of the tokens are found in toclauses. Therefore, we can conclude that the verb try in the try and $V$ construction is a finite verb of the clause.

The research result has offered a significant implication in the field of English grammar and the teaching of grammar in English as a foreign language (EFL) context. While native speakers of English acquire this type of unique grammatical construction, non-native speakers could not rely on language acquisition through language exposure for try and $V$ because its frequency is too small. In addition, it is more likely that EFL learners' standard English grammatical knowledge would block the acquisition on a rare form such as try and $V$ when they do encounter it in context. Therefore, this type of construction needs to be directly taught, and thus it has to be included in future editions of English grammar coursebooks. The transitivity of the verb occupying the $V$ position can be included as one of the subtopics in the coursebooks.

\section{Conclusion}

The research results have shown that the number of arguments for try and $V$ construction represents the number of arguments following the conjunction and rather than the verb try. Therefore, it can be concluded that the verb try is a finite verb in a clause, while the verb follows the conjunction and is a non-finite verb on which the argument is based. The result of this study confirms the previous prediction that try and $V$ construction is a paraphrase of try to $V$.

The results of this study have provided significant information in the field of English grammar. However, the generalizability of these results is subject to certain limitations. First, we did not have access to a new version of BNC, where more recent data have been added. Therefore, the frequency of try and $\mathrm{V}$ construction might be different if new BNC, i.e., BNC2014, was used. Therefore, future research is recommended to use more recent corpora. Second, this research only used two English dialects, i.e., British English and American English. Other English dialects such as Australian English and Canadian English might show different uses of try and $V$ in 
terms of its transitivity. Thus, it opens a potential for further research. Finally, the emergence of recognition for outer and expanding circle varieties of English creates a need to investigate try and $V$ construction in those English varieties. The current study has not considered this development, and therefore, further research is encouraged.

\section{References}

Akbarnezhad, S., Sadighi, F., \& Bagheri, M. S. (2020). A syntactic-based approach to the perception and production of English verbs' argument structures by Iranian EFL learners. Cogent Arts and Humanities, 7(1). https://doi.org/10.1080/23311983.2020.1770956

Al-Makatrah, E. S., Yasin, M. S. M., Sulaiman, M. Z., \& Al-Khawaldeh, M. (2017). The markedness in acquiring do-support in negation and inversion by adult nativeArabic speakers learning English. 3L: Language, Linguistics, Literature, 23(4), 143156. https://doi.org/10.17576/3L-2017-2304-11

Altakhaineh, A. R. M., \& Zibin, A. (2018). Verb + verb compound and serial verb construction in Jordanian Arabic (JA) and English. Lingua, 201, 45-56. https://doi.org/10.1016/j.lingua.2017.08.010

Anderson, J. M. (2013). On so-called "conjunctions" in English. Poznan Studies in Contemporary Linguistics, 49(1), 21-77. https:// doi.org/10.1515/psicl-2013-0002

Azar, B., \& Hagen, S. (2016). Understanding and using English grammar (5th ed.). New York: Pearson Education ESL.

Biber, D., Johansson, S., Leech, G., Conrad, S., \& Finegan, E. (1999). Longman grammar of spoken and written English. Harlow: Pearson Education Limited.

Bidgood, A., Pine, J., Rowland, C., Sala, G., Freudenthal, D., \& Ambridge, B. E. N. (2021). Verb argument structure overgeneralisations for the English intransitive and transitive constructions: Grammaticality judgments and production priming. Language and Cognition, 1-41. https://doi.org/10.1017/langcog.2021.8

Bolotov, V. I., Samorodova, E. A., Zakirova, E. S., \& Belyaeva, I. G. (2021). Peculiarities of mentality reflection through tense-aspect verb forms in russian and english languages. XLinguae, 14(2), 92-103. https:// doi.org/10.18355/XL.2021.14.02.07

Brook, M., \& Tagliamonte, S. A. (2016). Why does Canadian English use try to but British English use try and? Let's try and/to figure it out. American Speech, 91(3), 301-326. https://doi.org/10.1215/00031283-3701026

Carden, G., \& Pesetsky, D. (1977). Double-verb constructions, markedness and a fake co-ordination. In Papers from the 13th regional meeting of the Chicago Linguistic Society (pp. 82-92). Chicago.

Davies, M. (2013). Google Scholar and COCA-Academic: Two very different approaches to examining academic English. Journal of English for Academic Purposes, 12(3), 155-165. https:// doi.org/10.1016/j.jeap.2013.01.003

Davies, M. (2021). The TV and Movies corpora. International Journal of Corpus Linguistics, 26(1), 10-37. https:// doi.org/10.1075/ijcl.00035.dav

Desurmont, C. (2011). <TRY AND V>, structure de coordination. Anglophonia, 15(30), 11-21. https://doi.org/10.4000/anglophonia.369

Freudenthal, D., Ramscar, M., Leonard, L. B., \& Pine, J. M. (2021). Simulating the acquisition of verb inflection in typically developing children and children with developmental language disorder in English and Spanish. Cognitive Science, 45(3). https://doi.org/10.1111/cogs.12945 
Gebhardt, L. (2013). A constraint on preposition sequences in English complex predicates. Lingua, 135, 171-185. https:/ / doi.org/10.1016/j.lingua.2012.08.004

Gerwin, J. (2013). Give it me!: Pronominal ditransitives in English dialects. English Language and Linguistics, 17(3), 445-463. https://doi.org/10.1017/S1360674313000117

Hommerberg, C., \& Tottie, G. (2007). Try to or try and? Verb complementation in British and American English. ICAME Journal: Computers in English Linguistics, 31, 45-64.

Huddleston, R., Payne, J., \& Peterson, P. (2002). Coordination and supplementation. In R. Huddleston \& G. K. Pullum (Eds.), The Cambridge Grammar of the English Language (pp. 1273-1362). Cambridge: Cambridge University Press. https://doi.org/10.1017/9781316423530.016

Huddleston, R., \& Pullum, G. K. (2005). A student's introduction to English grammar. Cambridge: Cambridge University Press. https://doi.org/10.1017/CBO9780511815515

Huelva Unternbäumen, E. (2015). From primary metaphors to the complex semantic pole of grammatical constructions. Language and Cognition, 7(1), 68-97. https://doi.org/10.1017/langcog.2014.18

Jary, M., \& Kissine, M. (2019). Mood and the analysis of non-declarative sentences. In D. Wilson \& D. Sperber (Eds.), Relevance, Pragmatics and Interpretation (pp. 115126). Cambridge: Cambridge University Press. https://doi.org/10.1017/9781108290593.011

Kastronic, L., \& Poplack, S. (2021). Be that as it may: The unremarkable trajectory of the English bubjunctive in North American speech. Language Variation and Change, 33(1), 107-134. https:/ / doi.org/10.1017/S095439452100003X

Kim, H., \& Rah, Y. (2021). Applying constructionist approaches to teaching English argument structure constructions to EFL learners. TESOL Quarterly, 55(2), 568592. https:// doi.org/10.1002/tesq.3002

Kim, H., Shin, G. H., \& Hwang, H. (2020). Integration of verbal and constructional information in the second language processing of English dative constructions. Studies in Second Language Acquisition, 42(4), 825-847. https://doi.org/10.1017/S0272263119000743

Kristoffersen, K. E. (2011). Control and transitivity: A study of the Norwegian verb love "promise." In H. G. Simonsen \& R. T. Endresen (Eds.), A Cognitive Approach to the Verb (pp. 259-280). Berlin: De Gruyter Mouton. https://doi.org/doi:10.1515/9783110817461.259

Kroeger, P. R. (2004). Analyzing syntax. Cambridge: Cambridge University Press. https://doi.org/10.1017/CBO9780511801693

Launey, M., \& Mackay, C. (2011). Bitransitive verbs, ambitransitive verbs. In C. Mackay (Ed.), An Introduction to Classical Nahuatl (pp. 178-188). Cambridge: Cambridge University Press. https:// doi.org/10.1017/CBO9780511778001.022

Mair, C., \& Leech, G. N. (2021). Current Changes in English Syntax. In B. Aarts, A. McMahon, \& L. Hinrichs (Eds.), The Handbook of English Linguistics (2nd ed., pp. 249-276). New Jersey: John Wiley \& Sons Ltd. https://doi.org/10.1002/9780470753002.ch14

Matsumoto, N. (2020). Developing one corpus-based grammar textbook about 
irregular multi-verb sequences in English. International Journal of Applied Linguistics, 30(2), 264-282. https:/ / doi.org/10.1111/ijal.12322

McEnery, T., \& Hardie, A. (2014). Corpus linguistics: Method, theory and practice. Cambridge: Cambridge University Press. Retrieved from http://library.lol/main/2AB7728A0DF9CF03C96F73CF62649F4A

Newman, J., \& Rice, S. (2008). Asymmetry in English multi-verb sequences: A corpusbased approach. In B. Lewandowska-Tomaszczyk (Ed.), Asymmetric Events (pp. 3-23). Amsterdam: John Benjamins Publishing Company. https://doi.org/10.1075/celcr.11.03new

Nisbet, T. (2020). Meaning, metaphor, and argument structure. Journal of Linguistics, 56(3), 629-662. https:// doi.org/10.1017/S002222671900029X

Noble, C. H., Rowland, C. F., \& Pine, J. M. (2011). Comprehension of argument structure and semantic roles: Evidence from English-learning children and the forced-choice pointing paradigm. Cognitive Science, 35(5), 963-982. https://doi.org/10.1111/j.1551-6709.2011.01175.x

Radford, A. (1997). Syntactic theory and the structure of English: A Minimalist Approach. Cambridge: Cambridge University Press. https://doi.org/10.1017/CBO9781139166706

Rivière, A. M., Oetting, J. B., \& Roy, J. (2018). Effects of specific language impairment on a contrastive dialect structure: The case of infinitival to across various nonmainstream dialects of English. Journal of Speech, Language, and Hearing Research, 61(8), 1989-2001. https:/ / doi.org/10.1044/2018_JSLHR-L-17-0209

Roberts, J. R. (2012). Serial verbs in English: An RRG analysis of catenative verb constructions. Functions of Language, 19(2), 201-234. https://doi.org/10.1075/fol.19.2.03rob

Rodríguez-Ferreiro, J., Andreu, L., \& Sanz-Torrent, M. (2014). Argument structure and the representation of abstract semantics. PLoS ONE, 9(8). https://doi.org/10.1371/journal.pone.0104645

Ross, D. (2013). Dialectal variation and diachronic development of trycomplementation. Studies in the Linguistic Sciences: Illinois Working Papers, 108-147.

Ross, D. (2018). Small corpora and low-frequency phenomena: try and beyond contemporary, standard English. https://doi.org/10.4000/corpus.3574

Shin, G. H. (2017). Developmental aspects of English argument structure constructions for Korean-speaking second language learners: Usage-based constructional approaches to language development. Ampersand, 4, 10-20. https://doi.org/10.1016/j.amper.2017.02.001

Tallerman, M. (2020). Understanding syntax. Understanding Syntax (5th ed.). New York: Routledge. https://doi.org/10.4324/9781315758084

Tottie, G. (2012). On the history of try with verbal complements. In S. Chevalier \& T. Honegger (Eds.), Words, Words, Words: Philology and Beyond: Festschrift for Andreas Fischer on the Occasion of his 65th Birthday (pp. 199-214). Tübingen: Narr Francke Attempto.

Tsuchida, T. (2011). A theoretical analysis of the English "try and $V$ " construction. Retrieved from https:/ / files.eric.ed.gov/fulltext/ED518962.pdf

Walker, T. (2017). "he saith yt he thinkes $\mathrm{yt}^{\text {": }}$ Linguistic factors influencing third 
Faisal Mustafa, Syamsul Bahri Yusuf: Transitivity of Try and V Construction in British and American English

person singular present tense verb inflection in Early Modern English depositions.

Studia Neophilologica,

89(1),

133-146.

https://doi.org/10.1080/00393274.2016.1190298 